\title{
Testicular Torsion: Experience in a Tertiary Urology Referral Centre
}

\author{
(1) Sinharib Çitgez, (1) Birgi Ercili, (1) Uğur Aferin, (1) Ahmet Gürbüz, (1) Çetin Demirdağ, (1) Bülent Önal \\ Istanbul University-Cerrahpaşa, Cerrahpaşa Faculty of Medicine, Department of Urology, İstanbul, Turkiye
}

What's known on the subject? and What does the study add?

In this study, the risk factors for orchiectomy in patients with testicular torsion were investigated.

\begin{abstract}
Objective: To evaluate the patients who presented to our department due to testicular torsion (TT) and investigate the risk factors affecting orchiectomy in patients with $\pi$.

Materials and Methods: Between November 2005 and January 2018, the data of 46 male patients were analysed. The patients were divided into two groups: group 1, patients who underwent orchiectomy and group 2, patients who underwent detorsion and testicular fixation. The paternity rates between groups 1 and 2 were compared. Statistical analyses were performed to determine the risk factors for orchiectomy.

Results: The participants' mean age was 26.9 years. Of the cases, 35 (76.1\%) were determined between November and March, when diurnal temperature changes were observed. Orchiectomy was performed in 31 patients (group 1) and testicular detorsion and fixation in 15 (group 2 ). The overall orchiectomy rate was $67.4 \%$. The duration between the onset of complaints and the intervention was found to be the only risk factor for orchiectomy in $\Pi$. The paternity rate in groups 1 and 2 was $86.6 \%$ and $85.7 \%$, respectively $(p=1.0)$.

Conclusion: The prolongation between the onset of complaints and the application in $\Pi$ is a risk factor for orchiectomy. Prompt diagnosis and intervention are required in treatment. Regarding paternity rates, groups 1 and 2 appear similar.
\end{abstract}

Keywords: Testicular torsion, orchiectomy, risk factor

\section{Introduction}

Testicular torsion (T), which is typical in all age groups, is a common cause of urological emergencies (1). $\Pi$ may cause necrosis due to the deterioration of the blood supply to the testicle as a result of spermatic cord twisting. It is a condition requiring urgent treatment as it can cause organ damage. In differential diagnosis, there may be similar acute conditions such as appendix testis and epididymis torsion, infectious diseases such as epididymitis and epididymoorchitis and scrotal masses such as hydrocele, spermatocele, tumour and acute scrotal oedema (2). $\Pi$ could affect male fertility in adulthood and may be a critical cause of secondary male infertility (3). Laboratory analysis of semen samples has not shown adequate sperm count and sperm vitality in $>50 \%$ of patients with $\Pi$ (4).

This study aimed to retrospectively evaluate the patients who presented to our clinic due to $\Pi$ and analyse the risk factors that affect orchiectomy in patients treated for $\Pi$.

\section{Materials and Methods}

We retrospectively reviewed the records of $\Pi$ patients who underwent surgery between November 2005 and January 2018 in our clinic. A total of 46 male patients were included in the study. Clinical and demographic data such as age, the duration between the onset of complaints and intervention to the $\pi$ and body mass index and perioperative data were recorded. The patients were divided into two groups: group 1, patients who underwent orchiectomy and group 2, patients who had testicular detorsion and fixation.

The medical history and physical examination, laboratory and radiological findings of all patients admitted with suspected $\Pi$ were evaluated. The presence of blood flow or ischaemia was evaluated by scrotal colour doppler ultrasonography. Surgical exploration was planned for patients suspected to have T. After detorsion, circulation within the testis was observed by applying hot compress. If the testicle has returned to normal following

Correspondence: Sinharib Çitgez MD, İstanbul University-Cerrahpaşa, Cerrahpaşa Faculty of Medicine, Department of Urology, İstanbul, Turkiye Phone: +90 5323122377 E-mail: drsinharib@yahoo.com ORCID-ID: orcid.org/0000-0002-3897-2951 Received: 02.06 .2020 Accepted: 30.08 .2020

Cite this article as: Çitgez S, Ercili B, Aferin U, Gürbüz A, Demirdağ Ç, Önal B. Testicular Torsion: An Experience in a Tertiary Urology Referral Centre. J Urol Surg 2021;8(1):29-32.

๑Copyright 2020 by the Association of Urological Surgery / Journal of Urological Surgery published by Galenos Publishing House. 
detorsion, scrotal fixation was then performed (Figure 1). If necrosis was noted, an orchiectomy was conducted.

Patients in groups 1 and 2 were called by phone, and the paternity rates of their partners were determined. The inclusion criteria were being in a relationship with the intent to become pregnant for at least 1 year, age $>18$ years, and a normal contralateral testis. Conversely, patients with primary infertility, those who were unwilling to participate or unreachable, and those with a history of undescended testis and/or varicocele were excluded from the analysis.

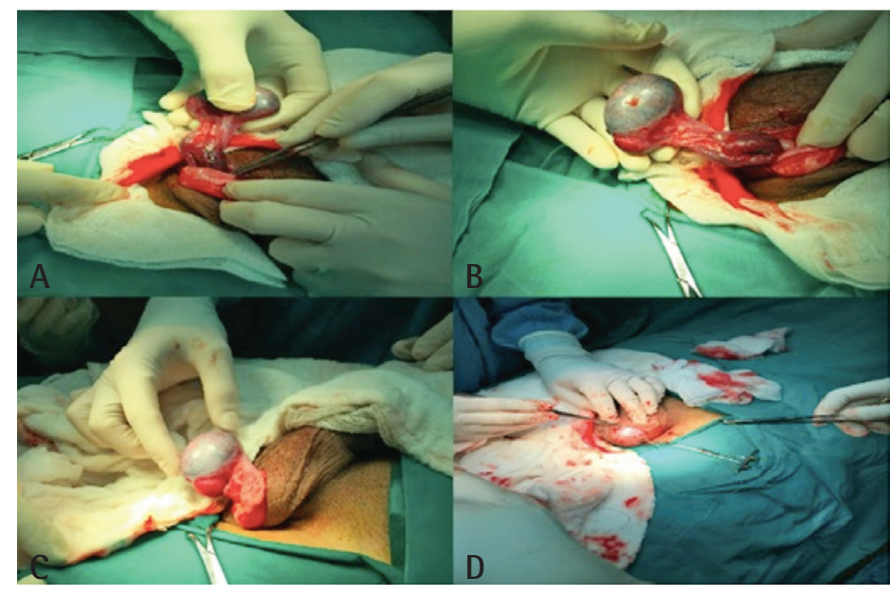

Figure 1. (A) Scrotal exploration of left T. (B) Surgical detorsion performed in the operating room. (C) Blood circulation observed in the testis after warm gauze application. (D) Scrotal fixation performed

П: Testicular torsion

\section{Statistical Analysis}

Statistical analyses were performed using the Statistical Package for the Social Sciences (SPSS) version 21.0 software (IBM SPSS Statistics for Windows, version 21.0. monk, NY: IBM Corp., Armonk, NY). Pearson's chi-square and Fisher's Exact tests were used to assess differences between the categorical variables, whereas the Kruskal-Wallis and Mann-Whitney $U$ tests were used to identify differences between the median values. A $p$-value $<0.05$ was considered statistically significant. An ethics committee approval was not sought owing to the retrospective design of the study. The consent form was filled in by all the participants and their families.

\section{Results}

The mean age of the patients was $26.90 \pm 7.61$. Of the patients, 31 were in group 1 and 15 in group 2. The demographic data is presented in Table 1. The mean follow-up time was 6.8 years (2-15). Among the patients, 27 had $\Pi$ on the left testicle and 19 had it on the right. The average time between the onset of complaints and admission to the hospital was 28.3 (6-38) hours.
The patients presented with scrotal pain and swelling. Prediagnosis of all the patients was made by physical examination and verified with scrotal colour doppler US. Two patients could not be diagnosed using scrotal colour doppler ultrasonography. In 76\% of cases (35 patients), the time of application was found to be at the time of diurnal temperature change (between November and March), and the orchiectomy rate was 67.4\% (31 patients).

In group 1 patients, diffuse haemorrhage and infarction were observed during surgery. In these patients, orchiectomy was performed because no testicular blood supply was noted following hot compress application and circulation control after at least 15 minutes after surgical detorsion. The time from the onset of complaints to hospital admission period was 30.7 (10-36) hours for group 1 and 16.7 (6-20) hours for group 2 $(p=0.001$, Table 2$)$.

A total of 22 patients were available for study inclusion criteria to compare paternity rate, including 15 and 7 in groups 1 and 2 , respectively. The paternity rate in groups 1 and 2 was $86.6 \%$ and $85.7 \%$, respectively $(p=1.0)$.

\section{Discussion}

$\Pi$ is an emergency medical condition that requires prompt and mandatory intervention. If therapeutic intervention is not provided immediately, testicular ischaemia and necrosis

\begin{tabular}{|c|c|}
\hline Patient characteristics & n \\
\hline No. of patients & 46 \\
\hline \multicolumn{2}{|l|}{ Age (year) } \\
\hline Mean (range) & $26.9(18-48)$ \\
\hline \multicolumn{2}{|l|}{ Side } \\
\hline Left & $27(58.7 \%)$ \\
\hline Right & $19(41.3 \%)$ \\
\hline \multicolumn{2}{|c|}{ The duration between the onset of complaints and application } \\
\hline Mean (range) & $28.3(6-38)$ \\
\hline \multicolumn{2}{|c|}{ Scrotal doppler US (ischaemia) } \\
\hline Yes & $44(95.6 \%)$ \\
\hline No & $2(4.4 \%)$ \\
\hline \multicolumn{2}{|l|}{ Operation time (min) } \\
\hline Mean (range) & $32.4(20-54)$ \\
\hline \multicolumn{2}{|c|}{ Diurnal temperature change } \\
\hline Yes & $35(76.1 \%)$ \\
\hline No & $11(23.9 \%)$ \\
\hline \multicolumn{2}{|c|}{ Hospitalisation time (days) } \\
\hline Mean (range) & $1.2(1-2)$ \\
\hline
\end{tabular}


Table 2. The predictive factors for orchiectomy in patients with $\Pi$

\begin{tabular}{|c|c|c|c|}
\hline & $\begin{array}{l}\text { Group } 1 \\
(n=31)\end{array}$ & $\begin{array}{l}\text { Group } 2 \\
(n=15)\end{array}$ & p-value \\
\hline \multicolumn{4}{|l|}{ Age (year) } \\
\hline Mean (+ SD) & $27.1 \pm 8.9$ & $26.2 \pm 6.6$ & 0.412 \\
\hline \multicolumn{4}{|c|}{ Operation time (min) } \\
\hline Mean (+ SD) & $32.5 \pm 17.4$ & $32.1 \pm 16.9$ & 0.256 \\
\hline \multicolumn{4}{|c|}{ Body mass index } \\
\hline Mean (+ SD) & $22.27 \pm 4.8$ & $22.82 \pm 4.6$ & 0.785 \\
\hline \multicolumn{4}{|c|}{ The duration between the onset of complaints and the application } \\
\hline Mean $( \pm S D)$ & $30.7 \pm 6.1$ & $14.8 \pm 1.1$ & 0.001 \\
\hline \multicolumn{4}{|c|}{ Hospitalisation time (days) } \\
\hline Mean $( \pm$ SD) & $1.2 \pm 0.8$ & $1.1 \pm 0.5$ & 0.878 \\
\hline \multicolumn{4}{|l|}{ Side } \\
\hline Left & 18 & 9 & \\
\hline Right & 14 & 5 & $>0.99$ \\
\hline \multicolumn{4}{|c|}{ Diurnal temperature change } \\
\hline Yes & 25 & 10 & \\
\hline No & 6 & 5 & $>0.99$ \\
\hline \multicolumn{4}{|c|}{ Scrotal Doppler US finding (ischaemia) } \\
\hline Yes & 30 & 14 & \\
\hline No & 1 & 1 & $>0.99$ \\
\hline
\end{tabular}

can occur (3). The duration and severity of the rotation of the spermatic cord are determining factors of tissue loss in the testicle. Based on the results obtained in experimental studies, a 720-degree torsion is required for complete cessation of blood flow from the testicular artery and the formation of ischaemia (4). If this happens, testicular infarction occurs as a result of venous occlusion, congestion and arterial ischaemia. Studies have shown that testicles are affected within 4-6 hours in case of blood flow cessation and necrosis begins after $12-16$ hours $(5,6)$. In cases that were intervened within the first 6 hours, the testicle could be preserved close to $100 \%$, whereas in cases intervened after 12 hours, preservation of the testicle was reported to decrease to $20 \%$ (7). In our study, the average time between the onset of complaints and admission to the hospital was found to be 28.3 (6-38) hours. This was found to be 30.7 (10-36) hours in group 1 and $16.7(6-20)$ hours in group 2 ( $p=0.001)$. Thus, it was seen that the duration of hospital admission was a risk factor for orchiectomy. The incidence of $\Pi \pi$ was reported as $1 / 4000$ before the age of 25; this rate decreases as the age increases (8). Depending on different etiological factors, $\Pi$ commonly occurs in the neonatal period and adolescence, between the ages of 12 and $18(8,9)$. The average age of patients in the study was found to be $26.90 \pm 7.61$. The reason for the relatively high average age was that the patients who presented to our clinic were adults. Paediatric patients are brought to the paediatric surgery department in our hospital. Left $\Pi T$ was detected in 27 cases and right $\Pi$ in 19 cases. Although the right/left ratio differs in the studies in literature, $\Pi$ is believed to be more common on the left. In a study of paediatric patients in our country (Turkiye) it was reported that $\Pi$ was seen more frequently in the left testicle than in the right (10).

The most crucial radiological method used in the diagnosis of $\Pi$ is scrotal colour doppler ultrasonography. However, higher sensitivity of scintigraphy has been overlooked due to the fact that it could not be applied easily in emergency conditions. It has been observed that arterial blood flow is lost in scrotal colour Doppler ultrasonography. Hypervascularization indicates inflammation. False-negative results can be detected in the early periods of $\Pi$, intermittent or incomplete torsions (11). Therefore, radiological evaluation should be considered together with clinical findings. In our study, false negativity was detected in scrotal colour doppler ultrasonography in two cases, one patient each in groups 1 and 2. These cases were found to be $\Pi$ after surgical exploration.

In $\Pi$ treatment, success is achieved by early diagnosis and detorsion in the fastest way, fixing both testicles to the scrotum. The most critical factor in determining testicular loss after $\Pi$ is the degree of torsion and how many hours it lasts. In our study, $67.4 \%$ of patients in group 1 required orchiectomy. Mansbach et al. (1) reported that they performed orchiectomy in $34 \%$ of $\Pi$ cases (762 of 2248), whereas Kandemir et al. (12) reported orchiectomy in $42.5 \%$ of $\Pi$ cases. The rate in our study appears to be higher (67.4\%) compared to the series in literature. We believe that the main reason for this is the delay of the application period. Additionally, it should be considered that our patient group did not include the neonatal and early childhood age group, contrary to the studies in literature. Therefore, new and further studies on this subject are warranted.

One of the secondary findings of our study; in $76 \%$ of $\Pi$ cases, the application time was in the period when diurnal temperature change was detected (between November and March). Hence, as hypothesised, $\Pi$ cases were found to commonly occur in winter and spring. When we look at the studies on this subject in the literature, Lu et al. (13) reported that the incidence of $\Pi$ was higher (77.5\%) when diurnal temperature changed, that is, in the winter and spring. Oxidative stress that develops in the presence of torsion causes necrosis in germinal cells and may cause infertility in the future (14). In studies, it has been reported that fertility is preserved in men who undergo detorsion in the early period ( $<13$ hours), whereas fertility is negatively affected in men who undergo orchiectomy in the late period (15). Additionally, spermatogenic damage to the ipsilateral testis may affect the contralateral testis (16-18). In particular, the theory that the opposite testicle is affected by the immunological mechanism is at the forefront (16). Furthermore, there are 
studies showing that fertility has not changed in patient groups with and without orchiectomy $(19,20)$. A study investigated paternity rates among 63 couples where the men had been treated for $\Pi$. The study found no decrease in paternity rates among $\Pi$ men when compared to the general population (21). To clearly determine the endocrine and exocrine function after $\Pi$, there is a need for larger prospective long-term follow-up studies using unselected control groups and reporting on future paternity rates. In our study, paternity rates between groups 1 and 2 were similar ( $86.6 \%$ vs $85.7 \%$, respectively; $p=1.0$ ).

\section{Study Limitations}

The present study had limitations including its long period of data collection, non-randomisation, and the relatively small number of cases in the subgroups and the study being a retrospective study. Moreover, the patients in our study showed only the patient profile in the urology clinic, and the small number was seen as a limitation in this study.

Furthermore, maternal factors were not included in this study. Despite these limitations, our results suggest that the duration between the onset of complaints and application in $\Pi$ is a risk factor for orchiectomy. Prompt diagnosis and intervention are required in treatment. However, we did not note significant differences regarding paternity rates between groups 1 and 2 . Future studies should be prospectively designed to overcome existing limitations.

\section{Conclusion}

In this retrospective study, the duration between the onset of complaints and application in $\Pi$ patients was found to be a risk factor for orchiectomy. Prompt recognition and treatment are necessary for testicular salvage.

\section{Ethics}

Ethics Committee Approval: An ethics committee approval was not sought owing to the retrospective design of the study.

Informed Consent: The consent form was filled in by all the participants and their families.

Peer-review: Internally peer-reviewed.

\section{Authorship Contributions}

Surgical and Medical Practices: S.Ç., Ç.D., B.Ö., Concept: S.Ç., Ç.D., B.Ö., Design: S.Ç., B.E., C..D., Data Collection or Processing: S.Ç., B.E., A.G., Analysis or Interpretation: U.A., A.G., Literature Search: S.Ç. Writing: S.Ç., B.E., Ç.D.

Conflict of Interest: No conflict of interest was declared by the authors.

Financial Disclosure: The authors declare that they have no relevant financial.

\section{References}

1. Mansbach JM, Forbes $P$, Peters $C$. Testicular torsion and risk factors for orchiectomy. Arch Pediatr Adolesc Med 2005;159:1167-1171.

2. McAndrew HF, Pemberton R, Kikiros CS, Gollow I. The incidence and investigation of acute scrotal problems in children. Pediatr Surg Int 2002;18:435-437.

3. Girgin R, Çınar Ö, Mungan NA. Are Haematological Parameters Reliable for Differential Diagnosis of Testicular Torsion and Epididymitis? Journal of Urological Surgery 2020;7:109-113.

4. Molokwu CN, Somani BK, Goodman CM. Outcomes of scrotal exploration for acute scrotal pain suspicious of testicular torsion: A consecutive case series of 173 patients. BJU Int 2011;107:990-993.

5. Djahangirian 0, Ouimet A, Saint-Vil D. Timing and surgical management of neonatal testicular torsions. J Pediatr Surg 2010;45:1012-1015.

6. Karakeçi A, Ozan T, Pirinçci N, Fırdolaş, F, Orhan i. 10-Year Single Center Experience in Testicular Torsion Cases. F.Ü Sağ. Bil. Tıp Derg 2019;33:39-42.

7. Coley BD. The acute pediatric scrotum. Ultrasound Clin 2006;1:485-496.

8. Kurt G, Cerrah Celayir A, Şahin C, Pelin K. Testis torsiyonlu olgularda 4.5 yıllık deneyimlerimiz. Zeynep Kamil Tıp Bülteni 2017;48:94-98.

9. Waldert M, Klatte T, Schmidbauer J, Remzi M, Lackner J, Marberger M. Color Doppler sonography reliably identifies testicular torsion in boys. Urology 2010;75:1170-1174.

10. Yapanoğlu T, Aydın HR, Adanur Ş, Polat Ö, Demirel A, Okyar G. Onüç yıllık çocukluk dönemi testis torsiyonu deneyimlerimiz. Eurasian J Emerg Med 2007;39:164-168.

11. Chen M, Esler R. Accuracy and Delay of Using Ultrasound in Testicular Torsion. J Urol Surg 2019;6:273-277.

12. Kandemir $A$, Balasar $M$, Ünlü $M Z$, Pişkin $M M$. Akut skrotumun önemli bir sebebi; testis torsiyonu: 7 yıllık deneyimlerimiz. The Cystoscope 2015;2:288293.

13. Lu Q, Ji C, Zhang G, Lian H, Zhang S, Li X, Gan W, Guo H. Clinical Analysis of 49 Cases With Testicular Torsion. Zhonghua Wai Ke Za Zhi 2015;53:599-602.

14. Melekos MD, Asbach HW, Markou SA. Etiology of Acute Scrotum in 100 Boys With Regard to Age Distribution. J Urol 1988;139:1023-1025.

15. Anderson MJ, Dunn JK, Lipschultz LI, Coburn M. Semen Quality and Endocrine Parameters After Acute Testicular Torsion. J Urol 1992;147:15451550.

16. Ozkan KU, Boran C, Kilinc M, Garipardiç M, Kurutaş EB. The Effect of Zinc Aspartate Pretreatment on Ischemia-Reperfusion Injury and Early Changes of Blood and Tissue Antioxidant Enzyme Activities After Unilateral Testicular Torsion-Detorsion. J Pediatr Surg 2004;39:91-95.

17. Gorur S, Helli A, Orhan İ. Testis torsiyonu patofizyolojisi ve tedavisinde yenilikler. Androloji Bülteni 2007;30:219-224.

18. Shiraishi K, Naito K, Yoshida K. Nitric Oxide Promotes Germ Cell Necrosis in the Delayed Phase After Experimental Testicular Torsion of Rat. Biol Reprod 2001;65:514-521.

19. Johnsen SG. Testicular biopsy score count--a method for registration of spermatogenesis in human testes: normal values and results in 335 hypogonadal males. Hormones 1970;1:2-25.

20. Ergur BU, Kiray M, Pekcetin C, Bagriyanik HA, Erbil G. Protective Effect of Erythropoietin Pretreatment in Testicular Ischemia-Reperfusion Injury in Rats. J Pediatr Surg 2008;43:722-728.

21. Wei SM, Yan ZZ. Zhou J. Beneficial Effect of Taurine on Testicular IschemiaReperfusion Injury in Rats. Urology 2007;70:1237-1242. 